\title{
Caracterización de la tipología familiar en los funcionarios de la Policía Nacional10
}

\section{Ángel Uriel Hernández González}

\section{Gonzalo Andrés Cortés Olarte}

Ms. Dirección y Gestión del Talento Humano Policía Nacional, Bogotá, Colombia

\section{Resumen}

El presente estudio tuvo como objetivo, describir y caracterizar la estructura y tipología familiar de los funcionarios que hacen parte de la Policía Nacional. Se utilizó un enfoque cuantitativo, con alcance descriptivo. En el estudio se analizaron los datos de 152.186 funcionarios, los cuales fueron extraídos del Sistema de Información para la Administración del Talento Humano "SIATH". Los resultados indican una diversificación de tipologías familiares, dentro de las cuales se evidencia mayor prevalencia de familias nucleares biparentales y familias unipersonales. Así mismo se evidenció una alta tasa de familias monoparentales en comparación con el resultado obtenido en la población colombiana según la Encuesta Nacional de Demografía y Salud ENDS 2015.

Palabras clave

Tipología familiar, nuclear biparental con hijos, unipersonal, monoparental, binuclear y homoparental.

10 Para citar este artículo: Hernández, A. y Cortés, G. (2021). Caracterización de la tipología familiar en los funcionarios de la Policía Nacional. Informes Psicológicos, 21(2), pp. 161-179http://dx.doi.org/10.18566/infpsic.v21n2a010 


\title{
Characterization of family typology in National Police officials
}

\begin{abstract}
The objective of this study was to describe and characterize the family structure and typology of the officials who are part of the National Police. A quantitative approach was used, with a descriptive scope. The study analyzed the data of 152,186 employees, which were extracted from the Information System for the Administration of Human Talent "SIATH". The results indicate a diversification of family typologies, within which a higher prevalence of two-parent nuclear families and one-person families is evidenced. Likewise, a high rate of single-parent families was evidenced in comparison with the result obtained in the Colombian population according to the National Demography and Health Survey ENDS 2015.
\end{abstract}

Keywords

Family typology, nuclear biparental with children, single, single parent, binuclear and homoparental.

\section{Caracterização da tipologia familiar nos funcionários da Polícia Nacional}

\section{Resumo}

0 objetivo deste estudo foi descrever e caracterizar a estrutura familiar e a tipologia dos funcionários que integram a Polícia Nacional. Foi utilizada uma abordagem quantitativa, com escopo descritivo. 0 estudo analisou os dados de 152.186 funcionários, extraídos do Sistema de Informação para a Administração de Talentos Humanos "SIATH". Os resultados indicam uma diversificação das tipologias familiares, nas quais se evidencia maior prevalência de famílias nucleares biparentais e de famílias unipessoais. Da mesma forma, foi evidenciada uma elevada taxa de famílias monoparentais em comparação com o resultado obtido na população colombiana de acordo com a Pesquisa Nacional de Demografia e Saúde ENDS 2015.

\section{Palavras chave}

Tipologia familiar, nuclear biparental com filhos, solteira, monoparental, binuclear e homoparental. 


\section{ntroducción}

Los fenómenos sociales presentes en los diferentes ámbitos de desarrollo humano, obedecen a las características contextuales del medio; es en este sentido como la evolución de las estructuras sociales, entre las cuales se encuentra la familiar, atraviesa diferentes etapas y niveles de desarrollo que se reflejan e interactúan en las dinámicas de relación entre los integrantes de la misma, dándole particularidades propias a cada núcleo familiar.

De acuerdo con Flórez y Cote (2015) en Colombia, al igual que en otros países latinoamericanos, la familia ha sufrido grandes transformaciones en los últimos años. Esto se debe según Arriagada (2002) y Benítez (2017) a factores sociales, económicos, políticos y culturales tales como la migración, la incorporación de la mujer al ámbito laboral, la revolución sexual, la globalización del mercado, la llegada del internet, entre otros cambios que han transformado las estructuras familiares.

Dentro de las nuevas configuraciones parentales, encontramos una variada retrospectiva histórica mucho más amplia de la que hubiera podido encontrarse algunos siglos antes (Vela, 2015). En este paisaje de diversidad familiar coexisten realidades familiares como lo son las familias extensas o nucleares, junto a otras tipologías más novedosas, entre las que podemos mencionar familia nuclear simple o sin hijos, familia monoparental, familia binuclear, familia homoparental, hogares unipersonales, entre otros (Ceballos, 2012).
La Policía Nacional de Colombia no escapa de esta realidad, pues cada uno de sus integrantes hacen parte de una sociedad y ésta, a su vez, tiene una gran influencia en la forma y estructura de las familias (Morgan, 1887). La Dirección de Talento Humano de la Policía Nacional, consciente de ello y alineada a las políticas misionales de la institución, busca conocer cómo están conformadas las familias de los funcionarios que prestan sus servicios a esta entidad, a fin de tener insumos científicos que permitan "crear y direccionar estrategias óptimas para el fortalecimiento del bienestar y la calidad de vida de los trabajadores y su grupo familiar" (Manual de Bienestar y Calidad de vida Policía Nacional de Colombia, 2016).

\section{Conceptualización}

E concepto de familia no es único, para tratar de comprender su significado, es necesario abordarlo desde una mirada holística, con sus interpretaciones y contextos. En este sentido, resulta importante conocer su significado etimológico el cual se muestra a continuación desde la mirada de diferentes autores.

De acuerdo a investigadores del tema, no se tiene un consenso claro sobre el origen etimológico de la palabra familia, algunos consideran que proviene del latín familiae que significa "grupo de siervos y esclavos patrimonio del jefe de la gens". En concepto de otros científicos, la palabra se deriva del latín fames (hambre) "Conjunto de personas que se alimentan juntas en la misma casa y a los que un pater familias tiene la obligación de alimentar" (Oliva \& Villa, 2014, p. 54). 
El término abrió su campo semántico para incluir también a la esposa e hijos del pater familias, a quien legalmente pertenecían, hasta que acabó reemplazando a gens (Enciclopedia Britanica en Español, 2009), que históricamente precedió a otras formas más avanzadas como las familias punalúa, sindiásmica, poligámica, monogámica y la actual o posmoderna; todas ellas con características organizativas distintas pero siempre conceptualizadas de manera similar (Oliva \& Villa, 2014). A continuación, se presentan algunos conceptos desde una mirada interdisciplinaria:

\section{Concepto biológico:}

Desde la biología se define la familia como una institución social anclada en necesidades humanas universales de base biológica donde hay prevalencia de la sexualidad, la reproducción para la conservación de la especie y la subsistencia (Jelin, 1998). Por otra parte, Oliva y Villa (2014) la definen como la unión de dos personas de sexo distinto que se unen con el fin de reproducirse. Para Valdivia-Sánchez (2008) la familia conyugal ha sido siempre conocida. Surge fundada en lo biológico para arropar a la madre e hijo y florece en todas las culturas de una pareja heterosexual de adultos y con fines de procreación.

\section{Concepto psicológico:}

Para la psicología, la familia es el primer contexto social donde el ser humano aprende a socializar, manejar sus emociones, moldear su carácter y desarrollar algunas características de su personalidad. Por otra parte Martínez (2001, citado en Valladares, 2008) la conceptualiza como una institución constituida por sistemas individuales que interactúan y constituyen, a su vez, un sistema abierto que intercambia constantemente energía e información con su medio. El psiquiatra Lauro Estrada Inda (2014) describe a la familia "como una célula social, cuya membrana protege en el interior a sus individuos y los relaciona al exterior con otros organismos semejantes" (p. 3).

\section{Concepto sociológico:}

Existen diversidad de conceptos desde esta disciplina, uno de los más aceptados por la comunidad científica es el realizado por Carbonnier (1991) donde considera a la familia como un conjunto de personas ligadas por el matrimonio o la filiación (relación de parentesco entre padres e hijos) o bien por personas vinculadas por lazos de consanguinidad (relación de sangre entre dos personas) o afinidades resultantes, a su vez, de relaciones matrimoniales o paternofamiliares. Algunos de los fines que tiene la familia desde esta mirada, según Oliva y Villa (2014) son: perpetuar costumbres, cultura e identidad social, respetar las normas sociales y crear una identidad basada en los roles y modelos de conducta socialmente aceptados.

\section{Concepto juridico:}

La Constitución Política de Colombia (1991) reconoce la familia como "nucleo fundamental de la sociedad. Se constituye por vínculos naturales o jurídicos, por la decisión libre de un hombre y una mujer de contraer matrimonio o por la voluntad responsable de conformarla" (Art. 42, p.20). 


\section{La familia en Colombia}

La familia en Colombia ha tenido un proceso de transformación de acuerdo a aspectos sociales, económicos, políticos y culturales. El "hablar de familia en un país marcado por su extrema diversidad geográfica, cultural y social es realmente difícil, tal como Virginia Gutiérrez lo planteó hace ya medio siglo, cuando participaba como delegada del Instituto Colombiano de Antropología" (Pachón, 2008, p. 146). A continuación, se pretende dar a conocer algunos de los aspectos más relevantes que impactaron en la transformación de las familias colombianas.

La llegada de los españoles al territorio colombiano trajo consigo nuevas costumbres que impactaron en la sociedad y en especial en la familia. La familia tradicional, enraizada en la religión católica, coge gran fuerza y es promovida por la ley 153 de 1887, norma que legitima los matrimonios católicos celebrados en Colombia. Para la época el matrimonio era percibido como un ascenso social (Echeverri, 2016).

Este modelo familiar fue acogido del derecho romano, donde Modestino, jurista célebre del siglo III d.C., establece que el matrimonio consiste en "la unión del hombre y de la mujer, implicando consorcio por toda la vida e igualdad de derechos divinos y humanos". En Colombia este modelo reforzó la figura patriarcal, haciendo del padre la única autoridad familiar de la que dependía la esposa y los hijos (Echeverri, 2016).

Ya para el siglo XX las tipologías familiares detectadas por varios investigadores en Colombia eran muy variadas, sin embargo, la patriarcal, extensa y prolífica predominaban en la época. La familia nuclear con hijos (padre, madre e hijos) era común en los sectores populares, mientras que la extensa (hogar donde habitan parientes cuyas relaciones no son únicamente entre padres e hijos) en los estratos medios y altos. De acuerdo con Pachón (2008) en el siglo XX las familias colombianas tenían muchos hijos, la natalidad y fecundidad eran altamente valoradas y el modelo era el de la familia cristiana.

La mujer era la encargada del hogar el cual debía manejar con austeridad, sencillez orden y aseo. Para el padre sus funciones se encontraban bien definidas, su espacio era el extradoméstico, el mundo de la política, los negocios y el trabajo. A lo largo de esta época las mujeres no tenían muchas opciones de vida: su futuro era ser esposas, religiosas o célibes, solteronas caritativas y beatas (Pachón, 2008, pp. 147-148).

A mediados del siglo $X X$, se presentaron grandes cambios en la familia, los avances en los métodos de planificación redujeron la natalidad y la familia ya podía planear cuántos hijos tener; la mujer empieza a salir lentamente del ámbito doméstico al laboral, se comienzan a dar los divorcios y los conflictos entre el ámbito laboral y familiar y aumento de las familias monoparentales (una madre o un padre con sus hijos). La investigadora Ximena Pachón (2008) relata que en este periodo de la historia los primeros casos de parejas separadas fueron criticados duramente, se les aplicó el ostracismo social, fueron excomulgadas por la curia y sus hijos fueron expulsados de los colegios. 


\section{Marco normativo}

Según Echeverri (2016), en 1968 ocurren dos acontecimientos trascendentales para la familia en Colombia. El primero se da con la promulgación de la ley 76 de 1968, la cual reconoce a la familia como elemento natural y fundamental de la sociedad, adquiriendo el derecho a la protección, y se establece que el matrimonio no podrá ser celebrado sin el libre consentimiento de los novios. El segundo suceso es la creación del Instituto Colombiano de Bienestar Familiar, mediante la ley 75 de 1968 y cuyo fin primordial fue: "trabajar por la prevención y protección integral de la primera infancia, la niñez, la adolescencia y el bienestar de las familias en Colombia" (Instituto Colombiano de Bienestar Familiar, 2019).

Arévalo (2014, citado por Echeverri, 2016), muestra una evolución cronológica de la familia. En 1974 mediante el decreto 2820 se otorga igualdad de derechos a hombres y mujeres; en el 1975 se celebra la ley quita sobre la adopción; en el año 1976 la ley 1 sobre divorcio y separación de cuerpos; en 1989 se publica el decreto 2272 que organizó la jurisdicción de familia; también en el mismo año se dio el decreto 2737 que da origen al Código del Menor; en el 1990 sale en vigencia la ley 54 que trata sobre la unión marital de hecho.

En 1991 la Constitución Política de Colombia, en su artículo 5, reconoce, sin discriminación alguna, la primacía de los derechos inalienables de la persona y ampara a la familia como institución básica de la sociedad. En 1993 se sanciona la Ley 82, que trata sobre la protección a la mujer cabeza de familia; en el 1996 se da la Ley 294 que castiga la violencia intrafamiliar. En el 2006 se publica la ley 1098 o Código de la Infancia y la Adolescencia (p. 39).

Para el año 2009 el Congreso de la República sanciona la Ley 1361 por medio de la cual se crea la ley de protección integral a la familia. La Corte Constitucional de Colombia (2011), mediante sentencia C-577/11 reconoce integralmente la entidad familiar de las parejas del mismo sexo y las hace acreedoras de la misma protección jurídica prevista a favor de las parejas heterosexuales.

El vínculo familiar se logra a partir de diversas situaciones de hecho, entre ellas la libre voluntad de conformar la familia, al margen del sexo o la orientación de sus integrantes. Por lo tanto, resulta claro que la heterosexualidad o la diferencia de sexo entre la pareja, e incluso la existencia de una, no es un aspecto definitorio de la familia, ni menos un requisito para su reconocimiento constitucional" (Corte Constitucional de Colombia, 2011, Sentencia T-716, p. 29).

"En adición, la Corte Constitucional Colombiana (2011) reconoce que el concepto de familia no solo abarca la constituida por un matrimonio de hombre y mujer (nuclear), sino que existen diferentes modalidades de conformarla" (Abello et al., 2018, p. 47).

En el 2017 la ley 1857 modifica la ley 1361 de 2009 "para adicionar y complementar las medidas de protección de la familia"; su objeto primordial es fortalecer 
y garantizar el desarrollo integral de la familia, como núcleo fundamental de la sociedad.

\section{Tipologia de estructura familiar}

La familia, como fundamento de la sociedad, es un sistema abierto que interactúa constantemente con los diferentes contextos sociales, económicos y culturales; cada contexto incide positiva o negativamente en su estructura.

En la actualidad el concepto de familia presenta una transformación sustancial en atención a los nuevos modelos sociales en que ésa se desarrolla, ya no se considera integrada exclusivamente por los parientes y los cónyuges como tradicionalmente se les identificaba, es decir, vinculada por matrimonio y relaciones parentales; ahora y en atención a la dinámica social, se contemplan otras formas de relaciones humanas, donde las personas que la integran se encuentran vinculados por lazos de afecto, de respeto, de convivencia y solidaridad (Oliva, 2013, p. 63).

Teniendo en cuenta los cambios que ha presentado la familia en los dos últimos siglos, a continuación se presenta la clasificación tipológica que realiza la Comisión Económica para América Latina y el Caribe CEPAL (2004), de acuerdo a las estructuras familiares:

Familia nuclear sin hijos: hogar integrado por una pareja sin hijos. Familia nuclear biparental con hijos: hogar conformado por el padre y la madre, con uno o más hijos.

Familia monoparental con jefatura masculina: hogar constituido por el jefe de hogar de sexo masculino y uno o más hijos de éste.

Familia monoparental con jefatura femenina: hogar constituido por el jefe de hogar de sexo femenino y uno o más hijos de éste.

Familia extensa: hogar que puede presentar un núcleo conyugal completo o incompleto más otros parientes (papa, mama, hijos, abuelos, tíos, primos).

Hogar unipersonal: hogar constituido por una persona sola.

Hogar sin núcleo conyugal: Este tipo de hogar se conforma por dos personas o más (grupo de estudiantes que comparten vivienda).

En cuanto a la familia reconstruida o binuclear nos basamos en el concepto de Silva (2007), quien la define como "el hogar en el cual uno o ambos miembros de la actual pareja tienen uno o varios hijos de uniones anteriores, en el que alguno o ambos han sido divorciados o viudos" (Silva, 2007, p. 1).

Ahora bien, para la clasificación de la homoparentalidad, se utilizó el concepto de los autores Acevedo, Marín, Heredia, Gómez y Múnera (2017), quienes la definen como "las familias conformadas por personas del mismo sexo. En esta familia sus miembros asumen compromisos de afecto, solidaridad, respeto, protección y asistencia, al igual que en las familias tradicionales" (p. 60). 


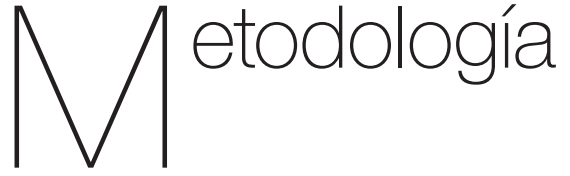

\section{Tipo de estudio}

El enfoque de esta investigación es de corte cuantitativo, su diseño metodológico es de tipo no experimental, transversal, basado en la recolección de los datos en un único momento. El estudio tiene un alcance descriptivo, puesto que se centra en fenómenos de la familia en el contexto policial, detallando cómo son y se manifiestan en la sociedad actual (Hernández, Fernández \& Baptista, 2014).

\section{Participantes}

Corresponde a todo el personal uniformado profesional y no uniformado que en el momento se encuentran en servicio activo en la Policía Nacional de Colombia. Teniendo en cuenta lo anterior, para este estudio se tomó como población objetivo a hombres y mujeres en los grados de Oficial, Suboficial, Mando Ejecutivo,
Patrullero, Agente, Personal No Uniformado en los niveles de Asesor, Profesional, Orientador, Técnico y Auxiliar; quienes laboran en los tres niveles de gestión de la institución: Administrativo, Operativo y Docente. Se excluyó el personal de Estudiantes del Nivel Ejecutivo, Cadetes, Alféreces y Auxiliares de Policía.

\section{Recolección y análisis de la información}

Los datos utilizados fueron extraídos del Sistema de Información para la Administración del Talento Humano (SIATH), a través de Oracle Discoverer y analizados a partir de IBM SPSS Modeler V. 17.

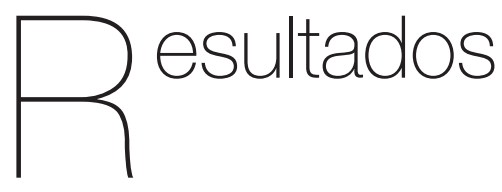

Representación hombres
y mujeres por categoría.

La población objeto de esta investigación está distribuida de acuerdo a la Tabla 1 anexa a continuación:

Tabla 1.

Representación de género por grado

\begin{tabular}{lccc}
\hline Grado & Mujer & Hombre & Total general \\
\hline Oficiales & 1.401 & 6.002 & 7.403 \\
\hline Suboficiales & 40 & 152 & 192 \\
\hline Mandos Ejecutivos & 1.990 & 40.661 & 42.651 \\
\hline Patrulleros & 9.474 & 87.602 & 97.076 \\
\hline Agentes & 8 & 591 & 599 \\
\hline No Uniformados & 3.040 & 1.225 & 4.265 \\
\hline Total general & 15.953 & 136.233 & 152.186
\end{tabular}

Fuente. Sistema de Información para la Administración del Talento Humano SIATH 


\section{Representación por estado civil \\ En la siguiente tabla se ubica la pobla- ción de acuerdo al género según su es- tado civil.}

Tabla 2.

Porcentaje por género según estado civil

\begin{tabular}{lccccc}
\hline \multirow{2}{*}{ Estado civil } & \multicolumn{2}{c}{ Mujeres } & \multicolumn{2}{c}{ Hombres } & \multirow{2}{*}{ Total general } \\
\cline { 2 - 5 } & Cantidad & Porcentaje & Cantidad & Porcentaje & \\
\hline Soltero & 10.654 & $67 \%$ & 62.003 & $46 \%$ & 72.657 \\
Casado & 3.497 & $22 \%$ & 44.504 & $33 \%$ & 48.001 \\
Unión Libre & 1.420 & $9 \%$ & 28.345 & $21 \%$ & 29.765 \\
Separado & 322 & $2 \%$ & 1.364 & $1 \%$ & 1.686 \\
Viudo & 60 & $.0037 \%$ & 17 & $.01 \%$ & 77 \\
\hline Total general & 15.953 & $100 \%$ & 136.233 & $100 \%$ & 152.186 \\
\hline
\end{tabular}

Fuente. Sistema de Información para la Administración del Talento Humano SIATH

\section{Estado civil por categoría}

Para los Oficiales, el $47 \%$ son casados, seguido de solteros, con el $34 \%$, en uniones maritales de hecho (18\%), divorciados (1\%), separados (.005\%) y viudos el (.0004\%). En la categoría de Suboficiales se encuentran el mayor porcentaje en los casados (68\%), en union libre (18\%), solteros (10\%), divorciados (2\%) y separados (2\%); mientras que para los Mandos Ejecutivos el 52\% es casado, en unión libre un $23 \%$, soltero permanece el $23 \%$, divorciado el $1 \%$, separados $1 \%$ y el $.004 \%$ viudos (ver Tabla 3).

Tabla 3.

Estado civil por categoría

\begin{tabular}{lcccccc}
\hline \multirow{2}{*}{ Grado } & \multicolumn{5}{c}{ Estado civil } & Total general \\
\cline { 2 - 5 } & Casado & Separado & Soltero & Unión Libre & Viudo & 7403 \\
\hline Oficiales & 3462 & 105 & 2504 & 1329 & 3 & 192 \\
Suboficiales & 131 & 8 & 19 & 34 & - & 42651 \\
Mandos E. & 22217 & 957 & 9833 & 9625 & 19 & 57076 \\
Patrulleros & 19819 & 519 & 58736 & 17997 & 5 & 599 \\
Agentes & 440 & 6 & 29 & 124 & - & 4265 \\
No Uniformados & 1932 & 91 & 1536 & 656 & 50 & 77 \\
\hline Total general & 48001 & 1686 & 72657 & 29765 & 152186 \\
\hline
\end{tabular}

Fuente. Sistema de Información para la Administración del Talento Humano SIATH 
De los Patrulleros, el 20\% es casado, $61 \%$ son solteros, en uniones maritales de hecho se encuentra el 19\%, separados el $.535 \%$, divorciados .002\% y viudos .005\%; el personal de Agentes en su mayoría es casado (73\%), y en unión libre con el 21\%; un 5\% permanece soltero, el 1\% divorciados y el .002\% separado. En cuanto a la categoría No Uniformados, su mayoría son casados (45\%), el $15 \%$ se encuentra en unión libre, el 36\% son solteros, y el 1\% divorciados, así como separados y viudos.
En cuanto a la característica sociodemográfica Policías con hijos, se encontró que, del total de los funcionarios participantes en el estudio, el 62\% (95.073) tienen hijos.

La Tabla 4 muestra la cantidad de policías que tienen hijos; evidenciando que un $86 \%$ de esta población, registra tener no más de dos.

Tabla 4.

Número de policías con determinado número de hijos.

\begin{tabular}{ccc}
\hline No. Hijos & Cantidad & Porcentaje \\
\hline 1 & 48.734 & $51 \%$ \\
2 & 32.804 & $34 \%$ \\
3 & 10.127 & $11 \%$ \\
4 & 2.499 & $3 \%$ \\
5 & 643 & $1 \%$ \\
6 & 185 & $.19 \%$ \\
7 & 58 & $.06 \%$ \\
8 & 12 & $.01 \%$ \\
9 & 6 & $.01 \%$ \\
10 & 3 & $.003 \%$ \\
11 & 2 & $.002 \%$ \\
\hline Total general & 95.073 & $100 \%$ \\
\hline
\end{tabular}

Fuente. Sistema de Información para la Administración del Talento Humano SIATH

Por otro lado, se realizó un análisis de la tasa porcentual de hijos por cada categoría, encontrando que para los Oficiales el porcentaje más alto recae sobre quienes tienen un (1) hijo, y representan el $57 \%$ de esta categoría; de igual manera, los Patrulleros con un 65\%.

Los uniformados con dos hijos, se ven representados por los Suboficiales con un 41\%, Mandos Ejecutivos con el $43 \%$ y el personal No Uniformado con un $45 \%$.

El porcentaje más alto de número de hijos por uniformado lo tienen los Agentes, quienes al tener tres hijos representan el 34\% en su categoría. 
Tabla 5.

Cantidad de hijos por categoría

\begin{tabular}{|c|c|c|c|c|c|c|c|c|c|c|c|c|}
\hline \multirow{2}{*}{ Grado } & \multicolumn{11}{|c|}{ Cantidad de hijos } & \multirow{2}{*}{$\begin{array}{l}\text { Total } \\
\text { general }\end{array}$} \\
\hline & 1 & 2 & 3 & 4 & 5 & 6 & 7 & 8 & 9 & 10 & 11 & \\
\hline Oficiales & 2.296 & 1.329 & 348 & 51 & 10 & 1 & - & - & - & - & - & 4.035 \\
\hline Suboficiales & 21 & 78 & 49 & 25 & 12 & - & 2 & - & 1 & - & - & 188 \\
\hline Mandos E. & 12.766 & 15.748 & 5.805 & 1.618 & 459 & 132 & 46 & 11 & 2 & 2 & - & 36.589 \\
\hline Patrulleros & 32.503 & 13.964 & 3.174 & 587 & 99 & 25 & 3 & 1 & - & - & - & 50.356 \\
\hline Agentes & 45 & 188 & 193 & 87 & 33 & 18 & 6 & - & 3 & 1 & 2 & 576 \\
\hline N. U. & 1.103 & 1.497 & 558 & 131 & 30 & 9 & 1 & - & - & - & - & 3.329 \\
\hline Total general & 48.734 & 32.804 & 10.127 & 2.499 & 643 & 185 & 58 & 12 & 6 & 3 & 2 & 95.073 \\
\hline
\end{tabular}

Fuente. Sistema de Información para la Administración del Talento Humano SIATH

Configuraciones tipológicas familiares: cifras Policía Nacional

A través de la información extraída del Sistema de Información de la Dirección de Talento Humano SIATH, se analizan las siguientes variables que ayudan al objetivo principal del informe el cual es conocer los tipos de familias presentes en la Institución.
Distribución de las familias de los policías según la tipología

A continuación, se muestran los porcentajes por tipología familiar de los funcionarios de la Policía Nacional, distribuidos en seis tipos, así: nuclear biparental con hijos, nuclear sin hijos, monoparental, binuclear (ensambladas o reconstruidas), unipersonal y homoparental.

Tabla 6.

Tipología familiar en la Policía Nacional

\begin{tabular}{lcc}
\hline Tipología familiar & Cantidad & Porcentaje \\
\hline Nucleares biparentales con hijos & 67.987 & $44.7 \%$ \\
Unipersonales & 48.322 & $31.8 \%$ \\
Monoparentales & 26.096 & $17.1 \%$ \\
Nuclear sin hijos & 8.767 & $5.8 \%$ \\
Binuclear (reconstruidas) & 990 & $.7 \%$ \\
Homoparentales & 24 & $.0001 \%$ \\
\hline Total General & 152.186 & $100 \%$ \\
\hline
\end{tabular}

Fuente. Sistema de Información para la Administración del Talento Humano SIATH

Como se puede evidenciar, la familia nuclear biparentales con hijos es el tipo de familia dominante en la Policía Nacional, con una representación del
44.7\%; seguida de las unipersonales con el 31.8\%; mientras que las familias monoparentales representan el $17.1 \%$. Por otra parte, las familias nucleares sin hijos 
tienen un porcentaje del 5.8\%. En cuanto a las familias binucleares su representación es menor, con un 1\% (990 familias), $y$, por último, se encuentran las familias homoparentales con 24 familias representantes (.0001\%).

\section{Distribución tipológica desagregada según la categoría del funcionario}

La distribución tipológica por categoría muestra los porcentajes de acuerdo a la jerarquía presente en la Institución, con el objetivo de analizar las configuraciones familiares de mayor y menor impacto en cada una de ellas, como se presenta a continuación:

\section{Categoría de Oficiales}

Las valoraciones tipológicas de la familia en la categoría de Oficiales arrojaron los siguientes resultados:

La Tabla 7 permite observar que los policías en el grado de Oficial en su mayoría conforman familias tradicionales, seguidos de policías que viven solos y de quienes reportan tener pareja, pero no hijos, representando el 92\% de esta población.

Tabla 7.

Tipología desagregada categoría de Oficiales

\begin{tabular}{lcc}
\hline Tipos de familia & Oficiales & Porcentaje \\
\hline Nucleares biparentales con hijos & 3.469 & $47 \%$ \\
Unipersonales & 2.106 & $28 \%$ \\
Nuclear sin hijos & 1.260 & $17 \%$ \\
Monoparentales & 506 & $7 \%$ \\
Binuclear & 60 & $.01 \%$ \\
Homoparentales & 2 & $.0002 \%$ \\
\hline Total general & 7.403 & $100 \%$ \\
\hline
\end{tabular}

Fuente. Sistema de Información para la Administración del Talento Humano SIATH

\section{Categoría Suboficiales}

Para esta categoría se evidencia que se mantiene la tendencia de la grados.

Tabla 8.

Tipologías desagregadas categoría de Suboficiales

\begin{tabular}{lcc}
\hline Tipos de familia & Suboficiales & Porcentaje \\
\hline Nucleares biparentales con hijos & 158 & $82 \%$ \\
Familias Monoparentales & 24 & $13 \%$ \\
\hline
\end{tabular}


Continuación

\begin{tabular}{lcc}
\hline Tipos de familia & Suboficiales & Porcentaje \\
\hline Familia binuclear & 6 & $3 \%$ \\
Unipersonales & 3 & $2 \%$ \\
Nuclear sin hijos & 1 & $.005 \%$ \\
Homoparentales & 0 & $0 \%$ \\
\hline Total general & 192 & $100 \%$ \\
\hline
\end{tabular}

Fuente. Sistema de Información para la Administración del Talento Humano SIATH

\section{Categoría Nivel Ejecutivo}

En los Mandos Ejecutivos, la familia nuclear biparental con hijos es la que tiene la mayor prevalencia; caso particular, la Monoparentalidad ocupa el segundo lugar lo que evidencia un aumento en la desestructuración de la familia tradicional, seguido de quienes en este nivel jerárquico optan por vivir solos.

Tabla 9.

Tipologías desagregadas Mandos del Nivel Ejecutivo

\begin{tabular}{lcc}
\hline Tipos de familia & Mandos E & Porcentaje \\
\hline Nucleares biparentales con hijos & 29.551 & $69 \%$ \\
Monoparentales & 6412 & $15 \%$ \\
Unipersonales & 4397 & $10 \%$ \\
Nuclear sin hijos & 1.656 & $4 \%$ \\
Binuclear & 626 & $1 \%$ \\
Homoparentales & 9 & $.0002 \%$ \\
\hline Total general & 42.651 & $100 \%$ \\
\hline
\end{tabular}

Fuente. Sistema de Información para la Administración del Talento Humano SIATH

\section{Categoría Patrullero}

En estos uniformados, la familia unipersonal tiene la mayor representatividad, lo que obedece a situaciones tales como rango de edad, nivel de ingresos, destinación nacional y niveles de rotación.

Tabla 10.

Tipologías desagregadas Patrullero (a)

\begin{tabular}{lcc}
\hline Tipos de familia & Patrulleros & Porcentaje \\
\hline Unipersonales & 41.134 & $42 \%$ \\
Nucleares biparentales con hijos & 31.961 & $33 \%$ \\
Monoparentales & 18126 & $19 \%$ \\
Nuclear sin hijos & 5576 & $6 \%$ \\
Binuclear & 269 & $.3 \%$ \\
Homoparentales & 10 & $.0001 \%$ \\
\hline Total general & 97.076 & $100 \%$ \\
\hline
\end{tabular}

Fuente. Sistema de Información para la Administración del Talento Humano SIATH 


\section{Categoría Agentes}

Los uniformados que ostentan este grado muestran una tendencia a conformar una familia nuclear biparental con hijos, están finalizando su permanencia institucional y mantienen pensamientos y comportamientos tradicionalistas.

Tabla 11.

Tipologías desagregadas categoría Agentes

\begin{tabular}{lcc}
\hline Tipos de familia & Agentes & Porcentaje \\
\hline Nucleares biparentales con hijos & 540 & $90 \%$ \\
Monoparentales & 25 & $4 \%$ \\
Nuclear sin hijos & 13 & $2 \%$ \\
Binuclear & 11 & $2 \%$ \\
Unipersonales & 10 & $2 \%$ \\
Homoparentales & 0 & $0 \%$ \\
\hline Total general & 599 & $100 \%$ \\
\hline
\end{tabular}

Fuente. Sistema de Información para la Administración del Talento Humano SIATH

\section{Categoría Personal No Uniformado}

Conforman un grupo poblacional maduro, su permanencia institucional es de largo plazo, mantienen comportamientos tradicionalistas y no se ven afectados por la rotación propia de la profesión policial.

Tabla 12.

Tipologías desagregadas categoría personal No Uniformado

\begin{tabular}{lcc}
\hline Tipos de familia & N.U & Porcentaje \\
\hline Nucleares biparentales con hijos & 2.308 & $54 \%$ \\
Monoparentales & 1.003 & $24 \%$ \\
Unipersonales & 674 & $16 \%$ \\
Nuclear sin hijos & 261 & $6 \%$ \\
Binuclear & 18 & $.0042 \%$ \\
Homoparentales & 1 & $.0002 \%$ \\
\hline Total general & 4.265 & $100 \%$ \\
\hline
\end{tabular}

Fuente. Sistema de Información para la Administración del Talento Humano SIATH

Principales hallazgos en las categorías

La categoría Agentes tiene la mayor representación de familias nucleares biparentales con hijos con el 90\%, mientras que la nuclear sin hijos la ocupan los Oficiales con un $17 \%$. En cuanto a la monoparental, los protagonistas son los No Uniformados con el $24 \%$ y para los hogares unipersonales, los Patrulleros con un $42 \%$. La familia binuclear tiene la mayor 
representación en los Mandos Ejecutivos con 626 familias y, por último, los hogares homoparentales son más comunes en los Patrulleros con 10 familias.

\section{Monoparentalidad en la Policía Nacional}

Como se mencionó en la Tabla 6, la familia monoparental se representa en la institución con un porcentaje del $17.1 \%$ (26.096); las familias monoparentales con jefatura femenina representan el 23\% (3.734), del total de las mujeres de la institución, mientras que la jefatura masculina con el 16\% (22.362) del total de hombres.

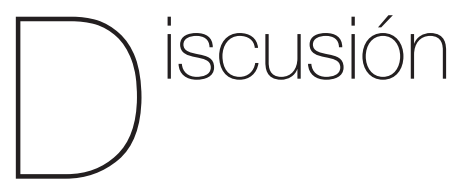

La familia en las últimas décadas ha sufrido grandes transformaciones a nivel mundial, esto debido a diversos cambios sociales, políticos, económicos y culturales. La familia nuclear biparental con hijos fue cediendo espacio a una creciente diversidad de tipologías familiares (UNICEF, 2003). En Colombia, de acuerdo a los resultados obtenidos por la Encuesta $\mathrm{Na}$ cional de Demografía y Salud 2015, se encontró que el 33.2\% de los hogares del país se encuentran ocupados por familias nucleares biparentales con hijos (Profamilia, 2015). En la Policía Nacional, este tipo de familia se representa con un $44.7 \%$, un $11.5 \%$ por encima de los resultados nacionales.
Por otra parte, entre 1990 y 2008 han cobrado relevancia otras formas de familias, como los hogares unipersonales, los cuales aumentaron del 6.6\% al 10.9\%. (Comisión Económica para América Latina y el Caribe (CEPAL), 2014). Para el año 2015, según Profamilia, el 11.2\% de los hogares del país están habitados por una sola persona. En el contexto policial este tipo de familia tiene una representación del $31.8 \%$, resultado que podría tener relación con el promedio de edad de los funcionarios el cual se encuentra entre los 20 y 28 años y, en su mayoría, son solteros.

Otro tipo de familia que en la actualidad tiene un crecimiento visible es la monoparental, la cual, según Giraldes, Penedo, Mertxe, y Zubeldia (1998), se forma por viudos/as y sus hijos, tras una ruptura matrimonial (separación y divorcio) y las surgidas a partir de un nacimiento fuera del matrimonio (madres solteras). Según Arriagada (2007), para el 2005 la monoparentalidad en América Latina se representó con un $13.1 \%$, de las que el $86.8 \%$ tenían jefatura femenina y un $13.2 \%$ jefatura masculina. De acuerdo a los resultados de la Encuesta Nacional de Demografía y Salud 2015, la familia monoparental está representada en Colombia por el 12.6\%; en cambio, para la Policía Nacional este porcentaje es del $17.1 \%$.

Ahora bien, la familia nuclear sin hijos también es protagonista en este escenario de la revolución de las nuevas tipologías familiares en Colombia. Según los datos publicados por Profamilia en la ENDS 2015, esta familia obtuvo un porcentaje de un $9.8 \%$ a nivel nacional, mientras que en la institución 
policial su porcentaje fue del 5.8\%. Como se puede evidenciar, las familias sin hijos siguen en aumento a través de los años; en palabras de Rondón (2015), no todos los tipos de uniones son formadas en función de la tenencia de hijos y, mucho menos por esto, dejan de considerarse familias. Las parejas también se forman por lazos sentimentales, unas metas, proyectos de vida en común, etc.

En cuanto a las familias binucleares o reconstituidas, en la cual uno o ambos miembros son divorciados, y tienen a su cargo uno o más hijos de su matrimonio anterior, se obtuvo a nivel nacional una disminución en los últimos años. Así, según la ENDS en el 2010 su porcentaje fue de $4.2 \%$ y en el 2015 de 3.2\%. Los funcionarios de la Policía Nacional mostraron solo un .7\% (990 parejas) en esta tipología, resultado considerado bajo en comparación con los expuestos en la ENDS 2015.

Para finalizar se exponen los resultados de las familias homoparentales la cuales continúan enfrentándose a un proceso de reconocimiento social. Este tipo de familia ha sido una de las más batalladas en los últimos años, no solo por su composición familiar sino por su reconocimiento legal, pues si bien en Colombia ya se aceptó el matrimonio homosexual y la adopción de los hijos biológicos de uno de los dos cónyuges, aún sigue siendo una población muy reducida en comparación con la población mundial (Correa \& Álvarez, 2016). En Colombia, la familia homoparental tiene una representación del .12\%, mientras que en la Policía Nacional tan solo 24 parejas son homoparentales.

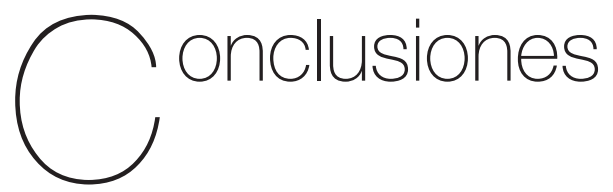

Con esta investigación se logró evidenciar que aun cuando en el contexto internacional y nacional las familias nucleares biparentales con hijos han disminuido, dentro de la familia policial se mantienen todavía en un porcentaje alto. Este tipo de familia es más frecuente en Suboficiales y Agentes.

Aunque la familia monoparental muestra un porcentaje alto, este resultado puede presentar sesgos, teniendo en cuenta que muchos de los funcionarios no reportan en el sistema a su pareja por diferentes motivos tales como:

- Tienen afiliado al sistema de salud DISAN a sus padres.

- $\quad$ Son casados con otro uniformado(a) o funcionario policial y al reportar su conyugue uno de los dos pierde el derecho a subsidio de vivienda.

- Por beneficios que otorga la Resolución 01360 de 2016 a los padres o madres cabeza de familia.

- Otros intereses particulares.

En cuanto a los hogares conformados por un solo individuo (unipersonales), en este estudio se observó un alto porcentaje. Uno de los factores que explica este comportamiento obedece al grupo etario en el cual se encuentra la mayoría de uniformados, quienes se ubican en edades comprendidas entre los 20 y 28 años, razón por la cual aún no conforman familia 
y continúan solteros; siendo los patrulleros quienes más conforman este tipo de hogar.

Respecto a la estructura familiar unipersonal en la institución, puede traer implícita otras tipologías como el familiar amplio (convivencia con padres, tíos o parientes cercanos), o las no familiares sin núcleo (convivencia con compañeros de trabajo) que son difíciles de identificar en el Sistema para la Administración del Talento Humano "SIATH".

Teniendo en cuenta los resultados obtenidos se puede concluir que las familias de los funcionarios de la Policía Nacional no escapan de la realidad en que viven los países latinoamericanos y, aunque no se tengan reportes de estudios anteriores sobre tipología familiar en la institución policial que nos permita llevar un seguimiento sobre la evolución o involución de ciertos tipos de familias, se logra evidenciar una alineación con las cifras obtenidas por la ENDS en 2015 en el contexto nacional.

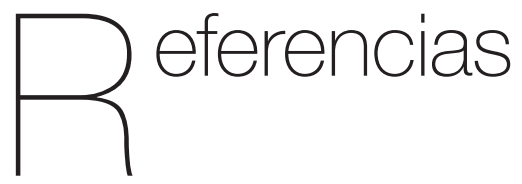

Abello, E., Bello, J., Guiza, A., Ortiz, A., Riveros, F., Vera, L., Bernal, A., \& Reyes, L. (2018). Actitudes hacia los niños adoptables por parte de familias monoparentales y nucleares de estratos 4, 5, y 6 en la Ciudad de Bogotá. Informes Psicológicos, 18(2), 45-62. http://dx.doi.org/10.18566/infpsic. v18n2a03
Acevedo, L., Marín, J., Heredia, D., Gómez, M., \& Múnera, N. (2017). La adopción homoparental en Colombia: presupuestos jurídicos y análisis de la idoneidad mental. Revista Anuario de Psicología Jurídica, 28(1), 58-65. https://doi.org/10.5093/ apj2018a8.

Arriagada, I. (2002). Cambios y desigualdad en las familias latinoamericanas. Revista de la CEPAL, 77, 144-146.

Arrieagada, I. (2004). Cambio de las familias en el marco de las transformaciones globales: necesidad de políticas públicas eficaces. Revista de la CEPAL, 42, 9-413.

Arriagada, I. (2007). Familias y politicas públicas en América Latina. Revista de la CEPAL, 96, 15-415.

Benítez, M. (2017). La familia: desde lo tradicional a lo discutible. Revista Novedades en Población, 13(26), 58-68.

Carbonnier, J. (1991). Derecho Civil, Relaciones Familiares y Cuasi Familiares. Barcelona, España: Bosch.

Ceballos, M. (2012). Ser padres y madres en familias homoparentales: análisis del discurso de sus percepciones sobre la educación de sus hijos e hijas. Revista de la Facultad de Educación de Albacete, 27, 143-158.

Comisión Económica para América Latina y el Caribe (CEPAL). (2014). Notas de Población No. 99 (LC/G.2628-P). Santiago de Chile.

Congreso de Colombia. (3 de diciembre de 2009). Ley de protección integral a la familia. (Ley 1361 de 2009). Recuperado de https://www.icbf.gov.co/cargues/avance/ docs/ley_1361_2009.htm 
Constitución política de Colombia. [Const.] (1991). Artículo 42 [ Título II]. 2da Ed. Legis.

Corte Constitucional de Colombia. (26 de julio de 2011). Sentencia C-577/2011. [MP. Gabriel Mendoza]. Recuperado de https://www.corteconstitucional.gov.co/ relatoria/2011/C-577-11.htm

Corte Constitucional (2011). (22 de septiembre de 2011). Sentencia T-716/2011. [Luis Vargas]. Recuperado de https:// www.corteconstitucional.gov.co/ relatoria/2011/t-716-11.htm

Correa, W., \& Álvarez , J. (2016). Diversidad Familiar en Colombia: Reflexiones sobre roles y funciones parentales en familias homoparentales en la ciudad de Medellín 2015-2016 (Tesis de Pregrado). Universidad de Antioquia. Medellín, Colombia.

Echeverri, S. (2016). Las tipologías familiares colombianas del siglo XXI: Un análisis de los vínculos familiares en las películas de animación infantil estrenadas en Colombia entre el 2009 y el 2016 (Tesis de Pregrado). Universidad de Medellín, Medellín, Colombia.

Estrada, L. (2014). El ciclo vital de la familia. Mexico: Penguin Random House Grupo Editorial México.

Flórez, C., \& Cote, H. (2015). Tipologías de familias en Colombia: Evolución 1993-2014. Departamento Nacional de Planeación - Observatorio de Políticas de las Familias-OPF. Recuperado de https://observatoriodefamilia.dnp.gov. co/Documents/Documentos\%20de\%20 trabajo/D3-tipologias-evolucion_dic3-(1). pdf.
Giraldes, M., Penedo, E., Mertxe, S., \& Zubeldia, U. (1998). La familia monoparental. Revista de servicios sociales, 35(1), 27-38.

Hernández, Fernández, \& Baptista. (2014). Metodología de la Investigación. Edición 6. México. Mc Graw Hill.

Jelin, E. (1998). Pany afectos. Latransformación de las familias. Revista Fondo de Cultura Económica, 2, 45-73.

Krader, L. (1979). Morgan: La Sociedad Antigua. Revista Nueva Antropología, 3(10), 13-39.

Oliva, E. (2013). El Divorcio incausado en México (Tesis de Maestría). Universidad Autónoma del Estado de Morelos, Distrito Federal, México.

Oliva, E., \& Villa, V. (2014). Hacia un concepto interdisciplinario de la familia en la globalización. Revista Justicia Juris, 10(1), 11-20.

Pachón, X. (2008). La familia en Colombia a lo largo del siglo XX (Tesis de Maestría). Universidad Nacional de Bogotá, Colombia.

Policía Nacional de Colombia. (2016). Manual de bienestar y calidad de vida para el personal de la Policía Nacional. Resolución No. 01360 de 2016, 8-9.

Profamilia. (2015). Encuesta nacional de demografía y salud ENDS. Bogotá.

Rondón, N. (2015). Nosotros decidimos ser dos: Familias sin hijos/as por elección. Bogotá: Universidad Santo Tomás.

Silva, M. (2007). Familias ensambladas. (Tesis de Posgrado). Escuela de Especialización 
de Asociación Gestáltica de Buenos Aires (AGBA). Buenos Aires, Argentina.

Ullmann, H., Maldonado, C., \& Nieves, M. (2010). La evolución de las estructuras familiares en América Latina, 1990 - 2010 los retos de la pobreza, la vulnerabilidad y el cuidado. Naciones Unidas-CEPAL: Santiago de Chile: División de Desarrollo Social - Series Políticas Sociales No. 193.

UNICEF. (2003). Nuevas formas de familia, perpectivas nacionales e internacionales. Montevideo, Uruguay.
Valdivia-Sánchez, C. (2008). La familia: concepto, cambios y nuevos modelos. La Revue du REDIF, 1(1), 15-22.

Vela, A. (2015). Del concepto jurídico de la familia en el marco de la jurisprudencia constitucional colombiana: un estudio comparado en América Latina. (Trabajo de Grado). Universidad Catolica, Bogotá, Colombia.

Valladares, A. (2008). La familia. Una mirada desde la Psicología. Revista Electrónica de las Ciencias Médicas en Cienfuegos, 6(1), 4-13. 